to carry out a breath test if there had been an accident or a traffic offence, as well as on occasions where the driver appeared to have been drinking, was approved by $\mathrm{Mr}$. B. R. Carr of the Canadian Ministry of Transport. It was not clear to the conference why the British police were dissuaded from waiting at times and places where there had almost certainly been heavy drinking.

The number of road casualties in young people is disproportionately high, and there was much evidence that alcohol is playing an increasingly important role in this context. In Ontario, for example, the legal drinking age had been reduced from 21 to 18 in 1971 and there had since been a sharp increase in drinking driving offences in the age group 16 to 19 . Experience in the U.S.A. had been similar, and the representatives of the Transport and Road Research Laboratory in England showed that here, too, blood alcohol levels had risen more sharply among young drivers than old. The discussion on the education of the public was therefore of special interest. Radio and television were widely used in some countries, especially in the U.S.A. It was not easy to assess their impact, and the evidence that they were effective was not substantial. One pilot project from Edmonton, Canada, seemed to show that a concerted campaign directed at social drinkers could give a reduction in alcohol-impaired driving. Clearly much more work is needed on the costs and benefits of education, but it seems that any tightening up of the law in the United Kingdom should be accompanied by a vigorous publicity campaign-the degree of enforcement of the law by the police is often higher when it is accepted by the driving public.

The conference was also concerned with the effects of drugs other than alcohol on driving. Alcohol is one of the few drugs which can both be estimated accurately in both blood and urine and for which there is a fairly precise relationship between blood levels and pharmacological effects. With other substances analysis may be difficult or impossible, and there may be differences in absorption, binding, and half life. The synergism between alcohol and the tranquillizers and barbiturates makes the combination of alcohol and drugs specially dangerous. Cannabis is widely taken in the U.S.A., but its importance in producing road accidents seems not so great as that of alcohol: it impairs attention and perception but does not seem to have much effect on risk taking.

Reviewing methods of breath analysis, Dr. K. Dubowski of Oklahoma accepted the evidence of the British workers that the blood-breath ratio for alcohol is $10 \%$ higher than that used at present in converting breath figures to blood figures. Several instruments in current use give blood alcohol results which are too low unless they are calibrated directly against known alcohol concentrations. New, reliable instruments are available, depending on fuel cells, and some are small and portable. The inaccuracy of the Alcotest breathalyser at present used by the police in the United Kingdom (but not in Northern Ireland) was the subject of adverse comment.

It was not universally agreed that a distinction can be made between the social drinker and the frank alcoholic, but it seems probable that many drivers with blood alcohol levels greater than $150 \mathrm{mg} / 100 \mathrm{ml}$ are alcoholics. Most of them should be offered treatment or given long periods of disqualification from driving.

Britain has already had successes in curbing the activities of the drinking driver. The committee set up by the Minister for Transport under the chairmanship of Mr. F. A. Blennerhassett, Q.C. should be able to suggest ways of improving the law and its enforcement so that further progress may be made.

\section{Oral Contraceptives and the Liver}

Oral contraceptive medication carries a small but definite risk to health, the most widely recognized problems being an increased incidence of venous thrombosis, pulmonary embolism, and cerebrovascular accident. ${ }^{1}$ Impairment of liver function may also occur, but all these complications have probably become less common since the introduction of low-oestrogen formulations. Many natural and synthetic oestrogens and synthetic progestogens are known to impair hepatic handling of bromsulphthalein, ${ }^{2}$ those with the configuration of 17- $\alpha$ alkyl substituted 19-norsteroids with a phenolic A ring being most consistently implicated, and most oral contraceptives contain mixtures of a synthetic oestrogen and progestogen having this structure. Up to $40 \%$ of healthy women taking these preparations will show increased retention of bromsulphthalein after a single intravenous injection, ${ }^{3}$ and when the maximum excretory capacity for bromsulphthalein was measured using an intravenous infusion technique some impairment was shown in all users of a variety of highoestrogen preparations. ${ }^{4} \mathrm{~A}$ slight and reversible rise in the serum aminotransferases or alkaline phosphatase may occur in some women during the first few weeks after starting oral contraceptives, ${ }^{5}$ and larger doses used in the treatment of malignant disease may be associated with the development of jaundice, ${ }^{6}$ though this is extremely rare in women taking the pill in normal dosage. A few of these patients have some form of underlying liver disease, but generally no such abnormality is present.

Jaundice induced by oral contraceptives is usually preceded by some days of malaise, anorexia, and nausea, and it almost always develops within the first six cycles of treatment. ${ }^{7}$ There is no fever or sign of a hypersensitivity reaction, and apart from jaundice and sometimes slight hepatic enlargement physical examination is negative. Liver function tests show a raised serum bilirubin and often a moderate rise in the serum aminotransferases, 237 though occasionally these may be raised to more than 1,000 units. ${ }^{8}$ The alkaline phosphatase is normal or slightly increased. Liver biopsy usually shows centrilobular canalicular and intracellular bile stasis with focal hepatic cell necrosis and scanty inflammatory cell infiltration. Recovery occurs within two months of withdrawal of the drug, but occasionally cholestasis persists for longer. ${ }^{9}$

It has been known for some years that genetic factors play a part in the pathogenesis of the jaundice in the cases in which there is no underlying liver disease. Thus it has been reported in two sisters ${ }^{9}$ and it is more common in Chile and parts of Scandinavia, areas where cholestasis of pregnancy is also more frequent, ${ }^{2}$ than in Britain or North America. The genetic predisposition has been elucidated further in a recent study from Stockholm ${ }^{10}$ in which the clinical and family histories of 129 women with oral contraceptive-induced jaundice were compared with a matched control population taking oral contraceptives who did not develop jaundice. The jaundiced women had experienced pruritus and jaundice in pregnancy significantly more often than the controls and the patients' mothers and sisters also experienced pruritus more frequently during pregnancy than their controls. It was of interest that gallstone symptoms and cholecystectomy had been more common in the jaundiced group and their sisters than in their respective controls. A high incidence of gallstones $(51 \%)$ has also been reported in another series of patients with recurrent cholestasis of pregnancy ${ }^{10}$ and an increased incidence was found recently in the Boston Collaborative Drug Surveillance 
Program among oral contraceptive users. ${ }^{11}$ Oral contraceptives can influence various factors concerned in biliary excretion such as hepatic uptake, metabolic conjugation, secretion, and the permeability of the biliary tree, ${ }^{12}$ and it seems likely that such changes may be important in the formation of lithogenic bile.

Both the oestrogen and progestogen components of the pill may be responsible for the cholestasis, ${ }^{2} 713$ and there is also some evidence from clinical studies for a synergistic effect. ${ }^{14}$ Synthetic progestogens such as chlormadinone ${ }^{15}$ and megestrol, ${ }^{14}$ which are derived from hydroxyprogesterone, are not 17- $\alpha$ substituted 19-norsteroids and do not produce jaundice. However, chlormadinone has been removed from the market because it produces breast tumours in dogs, and megestrol is used in only a few preparations. Oral contraceptive preparations containing only a low dose of progestogen (usually norethisterone) which are taken continually have recently been introduced and are still under evaluation. ${ }^{16}$

Three other possible rare hepatic complications of the use of oral contraceptives should be mentioned. Firstly, an increased incidence of neonatal jaundice has been reported in babies born to mothers who used oral contraceptives, though a more recent survey has failed to confirm this association. ${ }^{17}$ Secondly, a small number of cases, most often fatal, of thrombosis of the hepatic veins (Budd-Chiari syndrome) has been noted in young women on the pill. ${ }^{18}$ Finally, oral contraceptives are a possible cause of benign hepatic adenomata; this was discussed in an earlier leading article. ${ }^{19}$

What are the contraindications for oral contraceptive therapy in patients with a history of liver disease ? There seems to be no reason to withhold them in women with a history of viral hepatitis if the liver function tests have returned completely to normal. In women who have a history of pruritus or cholestatic jaundice of pregnancy or benign familial recurrent cholestasis there is a greater chance that cholestasis will develop during oral contraceptive therapy, ${ }^{4}$ but this is by no means invariable, and the risk may have been exaggerated. ${ }^{20}$ In this group of patients and those who have had one attack of cholestasis due to oral contraceptive therapy one of the new progestogen preparations may deserve a trial. In patients with pre-existing chronic liver disease, especially active chronic hepatitis and primary biliary cirrhosis, as well as in the Dubin-Johnson syndrome (a form of congenital hyperbilirubinaemia) oral contraceptive therapy may lead to a deterioration in liver function, ${ }^{4}$ and in these conditions other forms of contraception are to be preferred.

1 Lancet, 1974, 1, 1147.

2 Adlercreutz, H., and Tenhunen, R., American fournal of Medicine, 1970,

3 Ockner, R. K., and Davidson, C. S., New England fournal of Medicine, 1967, 276, 331 .

1967, 276, 331. Mowat, A. P., and Arias, I. M., fournal of Reproductive Medicine, 1969,
4.

3, 19.

- Stoll, B. A., Andrews, J. T., and Motteram, R., British Medical fournal, $1966,1,960$.

7 Drill, V. A., American fournal of Obstetrics and Gynecology, 1974, 119, 165.

8 Drill, V. A., American fournal of Obstetrics and Gynecology, 1974, 119, 165.

9 Somayaji, B. N., et al., British Medical Fournal, 1968, 2, 281.

10 Dalén, E., and Westerholm, B., Acta Medica Scandinavica, 1974, 195, 459.

11 Lancet, 1973, 1, 1399.

12 Smith, R. L., Acta Endocrinologica, 1974, suppl. no. 185, p. 149.

3 Urban, E., Frank, B. W., and Kern, F. jnr., Annals of Internal Medicine, $1968,68,598$.

14 Eisalo, A., Heino, A., and Räsänen, V., Acta Obstetrica et Gynaecologica Scandinavica, 1968, 47, 58.

15 Thompson, R. P. H., and Williams, R., British Medical fournal, 1970,

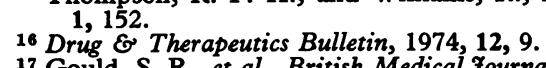

17 Gould, S. R., et al., British Medical fournal, 1974, 3, 228.

18 Hoyumpa, A. M. jun., Schiff, L., and Helfman, E. L., American fournal of Medicine, 1971, 50, 137.

19 British Medical fournal, 1974, 3, 3.

20 Rannevik, G., Jeppsson, S., and Vivllander, S., Fournal of Obstetrics and Gynaecology of the British Commonwealth, 1972, 79, 1128.

\section{Daunorubicin and the Heart}

Daunorubicin (rubidomycin) and the closely related adriamycin are antibiotics with a powerful cytotoxic action which is particularly effective in acute myeloblastic leukaemia but is useful also in a number of other leukaemias and sarcomas. The onset of cardiac failure in patients given daunorubicin has been recognized as a hazard of the drug ever since its introduction, but the picture has not been clear since many of the patients developing heart failure had also had advanced, uncontrolled sarcoma or leukaemia in relapse.

In a recent randomized controlled trial ${ }^{1}$ of treatment of childhood acute lymphocytic leukaemia the cardiac toxicity of daunorubicin was shown particularly clearly. Heart failure developed in 17 out of $172(9.9 \%)$ of the children, all of whom were in complete remission at the onset of cardiac symptoms. Six of the children treated with daunorubicin died from heart failure; none of those who had not received the drug showed any evidence of heart disease. In this series the mean dose of daunorubicin in the 17 children with signs of cardiac toxicity was $780 \mathrm{mg} / \mathrm{m}^{2}$ and ranged between 360 and $1260 \mathrm{mg} / \mathrm{m}^{2}$.

This and other studies ${ }^{2-6}$ have shown that the cardiac toxicity is dose-dependent in children, but in adults toxicity is less predictable and may develop abruptly despite low dosage. This greater susceptibility of older hearts is also well documented and heart failure in the elderly has been reported" 7-9 even in "safe" doses of only $55-200 \mathrm{mg} / \mathrm{m}^{2}$.

The importance of the interval between doses and the total duration of treatment in relation to the development of cardiac toxicity is still not clear. After an induction dose, maintenance treatment is usually given monthly. The onset of cardiac symptoms does not usually occur for between three and six months after starting treatment but may be delayed for weeks or even months after its end. In Halazun's study ${ }^{1}$ the time interval from the first dose of daunorubicin to the onset of cardiac toxicity ranged from 105 to 1,348 days and the time intervals from the last dose to the onset of signs of cardiac toxicity ranged between 18 and 280 days but was usually less than 100 days. Transient cardiac symptoms or abnormal signs during or after administration of the drug have not been reported but should be sought.

Heart failure induced by daunorubicin develops remarkably suddenly with sinus tachycardia, hypotension, dyspnoea, tachypnoea, and gallop rhythm, but no oedema at this stage. The chest radiograph may show little cardiac enlargement but there is usually some evidence of pulmonary venous congestion. Death may be swift. Patients who survive longer may develop cardiac dilatation and fluid retention; the initial response to diuretics is good, but deterioration usually follows. Early electrocardiographic changes are slight and easily missed: there is a fall in voltage followed by changes in the QRS and ST segments and T waves indicating abnormality in the depolarization and repolarization forces. With continuing heart failure changes occur in the $P$ waves due to left atrial or biatrial dilatation, but signs of ventricular hypertrophy or infarct-like patterns are absent, probably because the patients do not survive long once cardiac failure has developed.

Detailed studies of cardiac function have been very limited, but in Halazun's series systolic time intervals had been measured showing changes attributable to diminishing myocardial contractile efficiency with slowed velocity of contraction and diminishing stroke volume. At necropsy the hearts usually showed some generalized dilatation, but even this may be absent when death comes rapidly after the onset of cardiac failure. Ventricular mural thrombosis is sometimes seen and 